\title{
CLOUDCLASSROOM (CCR), FOR THE NEXT GENERATION
}

\author{
Chun-Yen Chang \\ Science Education Center, National Taiwan Normal University \\ No. 88, Sec. 4, Ting-Chou Rd., Wunshan District, Taipei, Taiwan
}

\begin{abstract}
This poster presentation aims to demonstrate an advanced version of clickers, CloudClassRoom (CCR), to conference participants. CCR is written in HTML 5.0 and works on every Internet-capable device without software or plug-ins installation. CCR enables teachers and students to participate in question-answering activates by using their own mobile devices, such as laptops, smartphones, or tablets. By this means, every student in the classroom can express his/her thoughts instantly as well as anonymously. CCR provides the teacher a rough picture of student learning progress in real time. Leveraging the capacity of mobile devices, CCR supports text and multimedia responses. Moreover, CCR is equipped with a role-swapping function; students are endowed with the power to pose questions to the teacher and peers, and then collect responses instantly from the whole class. We expect that the role-swapping function can engage students in deeper learning. The advanced functions of CCR will be demonstrated live, during the poster presentation.
\end{abstract}

\section{KEYWORDS}

Clicker, Instant Response System, Smart Phone, Classroom Learning, Group Discussion, Cloud Classroom

\section{INTRODUCTION}

According to the report conducted by the Ministry of Education in Taiwan (2015), the percentages of students who possess their own smart phone devices include $48.7 \%$ of elementary school students, $78.8 \%$ of junior high-school students, and $93.3 \%$ of senior high-school students. The average time students spent on the Internet per school day is more than 45 minutes. As of March 2017, recent statistics from the Internet World Stats (2017) reveal that Taiwan's Internet users account for $88 \%$ of the total population. Given the prevalence of smart phone devices and Internet usage, more and more schools start embracing the Bring-Your-Own Device (BYOD) policy to make learning more enjoyable and effective. Along with this trend, my research group has developed the CloudClassRoom (CCR) to transform smart phone devices into powerful interactive tools for classroom learning. CCR works on every Internet-capable device without further software or plug-in installation(s). It operates across-platforms, including iOS, Android, and Windows, regardless of the computer system being used. Once the teacher connects his/her device to CCR, he/she can easily initiate anonymous quizzes. In addition to the traditional, forced-choice answer format, CCR enables students to respond with short texts, pictures, or even emoticons. Students' answers are automatically aggregated and analyzed, providing the teacher with a rough picture of student learning progress just in time. To date, approximately 40,000 teachers and students have registered in CCR. More than 330,000 classroom activities have been conducted by using CCR. Thirteen different language versions of CCR have been released, including Chinese, English, Estonian, French, German, Indonesian, Japanese, Macedonian, Montenegro, Korean, Spanish, Thai, and Vietnamese.

\section{STRENGTHS OF CCR}

CCR is an advanced version of clickers, formally called instant response devices, designed to collect students' responses to in-class questions. Once the teacher poses a question, generally a multiple-choice type inquiry, students can use clickers to vote on the answers they prefer. A central monitoring system then 
automatically aggregates a histogram of students' votes, providing the teacher with the information about how well students currently understand the learning material. Several reviews (e.g., Chien et al., accepted; Kay \& LeSage, 2009) have indicated that the use of clickers can nurtures a sense of classroom participation and thus makes students feel accountable to the academic task exercised in the class. Moreover, the real-time data collected by clickers can assist teachers in tailoring feedback to address students' difficulties in real time. However, to deploy traditional clickers into every classroom, schools have to invest a lot of money for buying or renting hardware. Furthermore, the distribution and safekeeping of clickers are not easy tasks for teachers. To solve the aforementioned difficulties, we have therefore developed CloudClassRoom (CCR) that transforms personal mobile devices into clickers with ease (Chien \& Chang, 2015; Chien et al., 2015). CCR is written in HTML 5.0 and it runs on MySQL and PHP-enabled Apache servers. CCR, therefor, enables teachers and students interact with each other by using their own mobile devices, such as laptops, smartphones, or tablets, without software or plug-ins installation(s). Such a solution will become more cost-effective as more and more schools start embracing the Bring-Your-Own-Device (BYOD) policy (Johnson et al., 2014). Moreover, the question formats are not limited to just true-false and multiple-choice questions anymore. CCR facilitates open-ended questions because textual responses are enabled through the use of laptops, smart phones, or tablets. Answering open-ended questions, compared to true-false and multiple-choice questions, is a more effective way to stimulate students' higher-order thinking (Brookhart, 2010). Students can also upload photos, snapshotting either their own drawing or those of others, to CCR as their responses. Compared to solely accepting textual responses, asking students also to turn in photographic responses can make students more cognitively engaged and provide teachers with more information to evaluate students' understanding (Van Meter \& Garner, 2005). In terms of obtaining learning analytics on a large-scale manner, CCR is a far better research tool than traditional clickers are. Since CCR operates on clouds, researchers are enabled to use one central monitoring system to access all students' data, regardless of where the data is collected from, or from which classroom. This system design also facilitates national or even global level research on learning analytics obtained from real classrooms.

\section{INNOVATIVE PEDAGOGICAL USE}

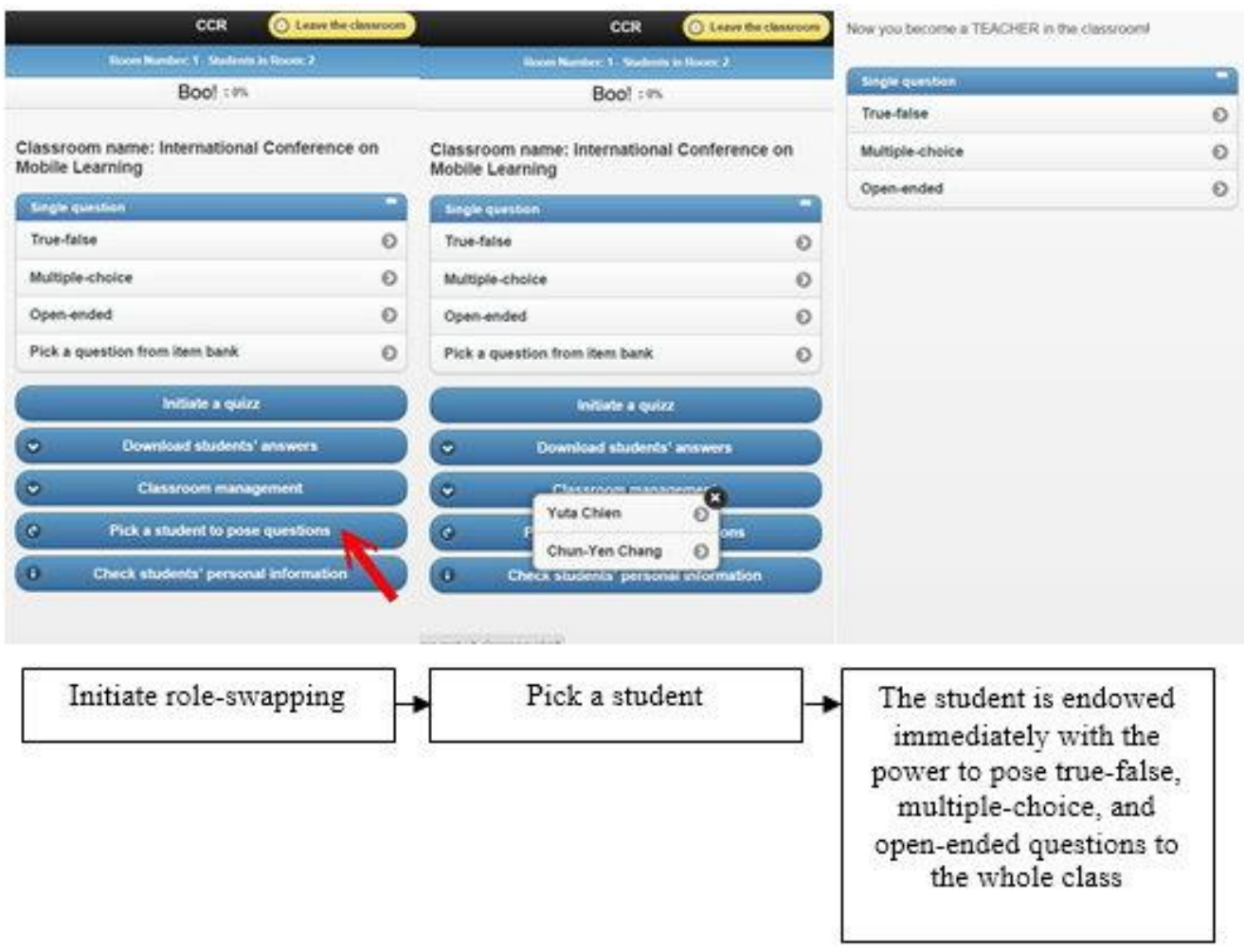

Figure 1. The Role-swapping Function of CCR 
CCR enables innovative instructional methods that are difficult to be implemented with traditional clickers. For instance, as shown in Figure 1, CCR is equipped with a role-swapping function. The teacher can use CCR to pick a student to pose questions. Once a student is appointed, he/she will be endowed immediately with the power to pose true-false, multiple-choice, and open-ended questions to the whole class by using CCR. He/she will be also able to collect, inspect, and broadcast peers' responses. We expect that the role-swapping function can engage students in deeper learning since previous literature (Brown \& Walter, 2005; Cunningham, 2004; Kilpatrick, 1987; Perrin, 2007) has suggested that asking students to generate questions can foster greater learner agency, reflection, responsibility, insight, ownership, and engagement. We will give conference participants a live demonstration of CCR. CCR is a promising tool to improve the interactivity of East Asian classrooms, in which students are usually silent and hesitate to express their ideas out loud. Therefore, my team is currently leading an international project to investigate the impact of CCR on classroom learning across Taiwan, Thailand, Vietnam, and other Asian countries. It is expected that the results can inform researchers, teachers, and policy makers in terms of how to better leverage the potential of mobile technology to boost learning and teaching.

\section{ACKNOWLEDGEMENT}

This work was financially supported by the "Institute for Research Excellence in Learning Sciences" of National Taiwan Normal University (NTNU) from The Featured Areas Research Center Program within the framework of the Higher Education Sprout Project by the Ministry of Education (MOE) in Taiwan

\section{REFERENCES}

Brookhart, S. M., 2010. How to assess higher-order thinking skills in your classroom. ASCD, Alexandria, USA.

Brown, S. I. and Walter, M. I. 2005. The art of problem posing. Psychology Press, Mahwah, USA.

Chien, Y. T. et al., 2015. Examining the effects of displaying clicker voting results on high school students' voting behaviors, discussion processes, and learning outcomes. Eurasia Journal of Mathematics, Science \& Technology Education, Vol. 11, No. 5, pp. 1089-1104.

Chien, Y. T. and Chang, C. Y., 2015. Supporting socio-scientific argumentation in the classroom through automatic group formation based on students' real-time responses. In M. S. Khine (Ed.), Science education in East Asia: Pedagogical innovations and research-informed practices (pp. 549-563). Springer International Publishing.

Chien, Y. T. et al, accepted. Do we click in the right way? A meta-analytic review of clicker-integrated instruction. Educational Research Review.

Cunningham, R. F. 2004. Problem posing: An opportunity for increasing student responsibility. Mathematics and Computer Education, Vol. 38, No. 1, pp. 83-89.

Johnson, L. et al., 2014. NMC horizon report: 2014 K-12 edition. The New Media Consortium, Austin, USA.

Kay, R. H. and LeSage, A., 2009. Examining the benefits and challenges of using audience response systems: A review of the literature. Computers \& Education, Vol. 53, No. 3, pp. 819-827.

Kilpatrick, J. 1987. Problem formulating: Where do good problems come from? In A. H. Schoenfeld (Ed.), Cognitive science and mathematics education (pp. 123-147). Lawrence Erlbaum Associates, Hillsdale, USA.

MOE. (2015). Students' Internet Usage Survey Report in 2015 [translated from Chinese].

Perrin, J. R. 2007. Problem posing at all levels in the calculus classroom. School Science and Mathematics, Vol. 107, No. 5, pp. 182-192.

Van Meter, P. and Garner, J., 2005. The promise and practice of learner-generated drawing: Literature review and synthesis. Educational Psychology Review, Vol. 17, No. 4, pp. 285-325.

IWS. (2017). Internet Usage in Asia. Internet World Stats: Usage and Population Statistics (IWS). Retrieved from: http://www.Internetworldstats.com/stats3.htm [Accessed May 17, 2017]. 